\title{
O BANCO DE DADOS
}

Esta publicação é um produto do Banco de Dados sobre iniciativas inovadoras em governos subnacionais, que tem como objetivo trazer a público informações a respeito da administração pública brasileira reunidas pelo Programa GESTÃO PÚBLICA E CIDADANIA. Ele constitui o principal produto do Programa uma vez que o maior objetivo deste é a ampliação do estoque de conhecimento sobre experiências alternativas em governos subnacionais, através da identificação e da disseminação do que está dando certo na administração pública brasileira.

Para todos os 1.557 programas, projetos ou atividades que participaram dos três primeiros Ciclos de Premiação (1996, 1997 e 1998), o Banco dispõe das informações constantes nas fichas de inscrição, cujos dados foram fornecidos por ocasião do envio do material para o processo de seleção. O Banco dispõe também de documentação na forma de relatórios, análises, materiais de divulgação, cópias de matérias jornalísticas, fitas de vídeo etc. relativa a diversos programas que enviaram material adicional (ver quadro I, p.22).

Para os 300 programas, projetos ou atividades classificados para a fase semifinal em cada um dos três anos (100 em cada Ciclo de Premiação) foram obtidas informações mais detalhadas, uma vez que os responsáveis pelas inscrições tiveram que responder um questionário-padrão remetido pelo Programa (ver quadro III, p.24).

Dessa forma, o Banco reúne um conjunto de informações padronizadas que permite a comparabilidade entre as diversas experiências, possibilitando visualizar as mais recentes tendências na execução das políticas públicas por parte dos governos subnacionais brasileiros. $\mathrm{Na}$ forma em que está organizado, o Banco permite, de acordo com as necessidades de cada interessado, executar uma pré-seleção da documentação a ser pesquisada a partir de consultas por área de atuação governamental, nível de governo (ver quadro II, p.23), área geográfica etc., disponibilizando uma variada gama de informações - mais completas para finalistas e semifinalistas - bastante úteis à consulta de gestores, pesquisadores, ocupantes de cargos públicos e cidadãos em geral.

Além da própria consulta aos originais e às publicações, são três as possibilidades de acesso dos interessados ao material disponível no Banco de Dados, conforme detalhado no quadro I:

- pela internet, no site http://inovando.fgvsp.br (atenção: não digitar o usual www); 
- por fax - (011) 287-5095 - poderão ser enviadas gratuitamente as informações constantes nas fichas de inscrição de até seis destes mesmos programas;

- por correio, ou pessoalmente, poderão ser atendidos pedidos de cópias do material disponível, cobrando-se apenas os custos de reprodução e postagem.

QUADRO | - Formas de acesso às informações disponíveis no Banco de Dados do Programa GESTÃO PÚBLICA E CIDADANIA

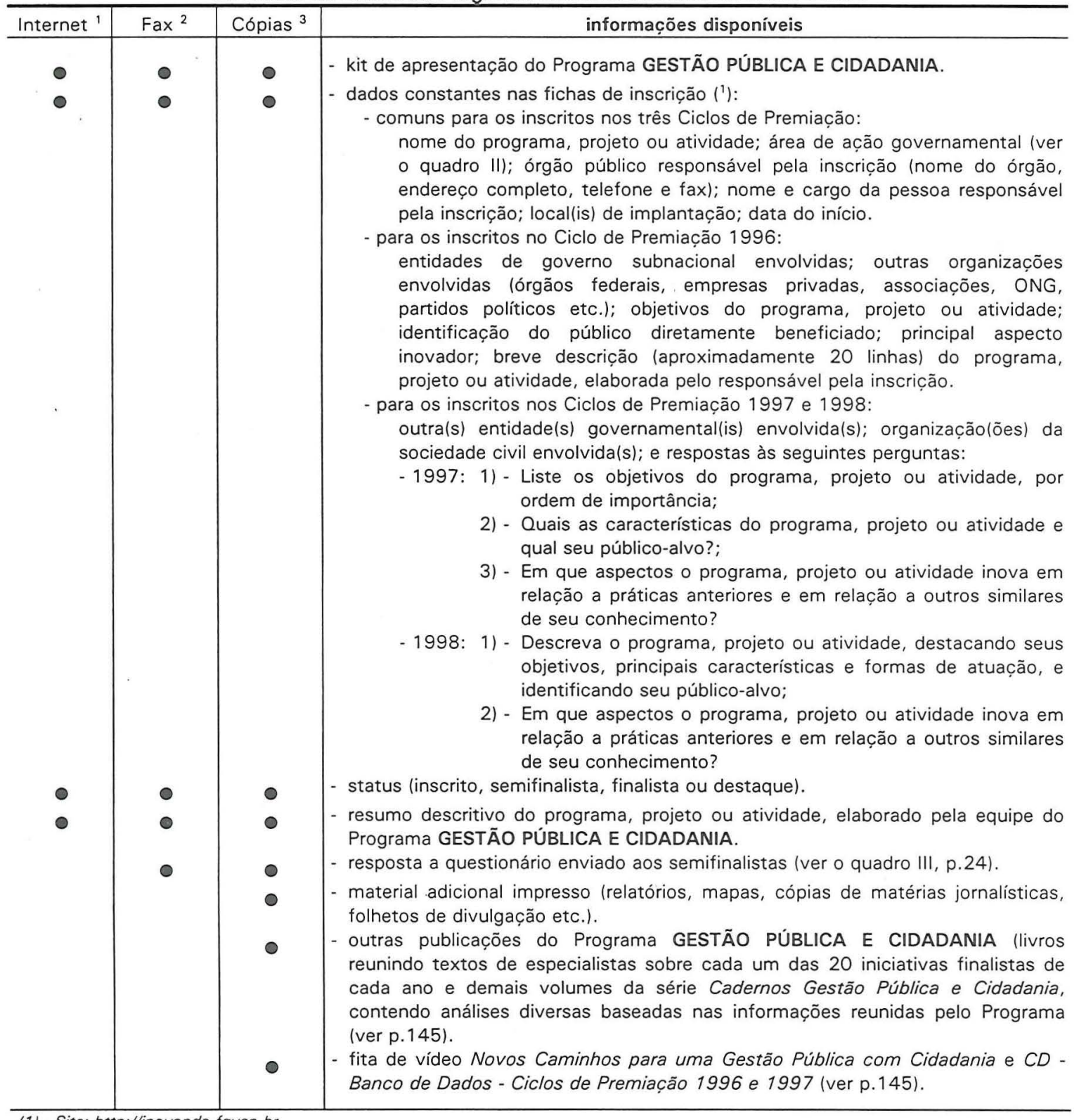


QUADRO II - Códigos de área (') de atuação governamental dos programas, projetos e atividades inscritos no Ciclo de Premiação 1998 do GESTÃo PÚBLICA E CIDADANIA

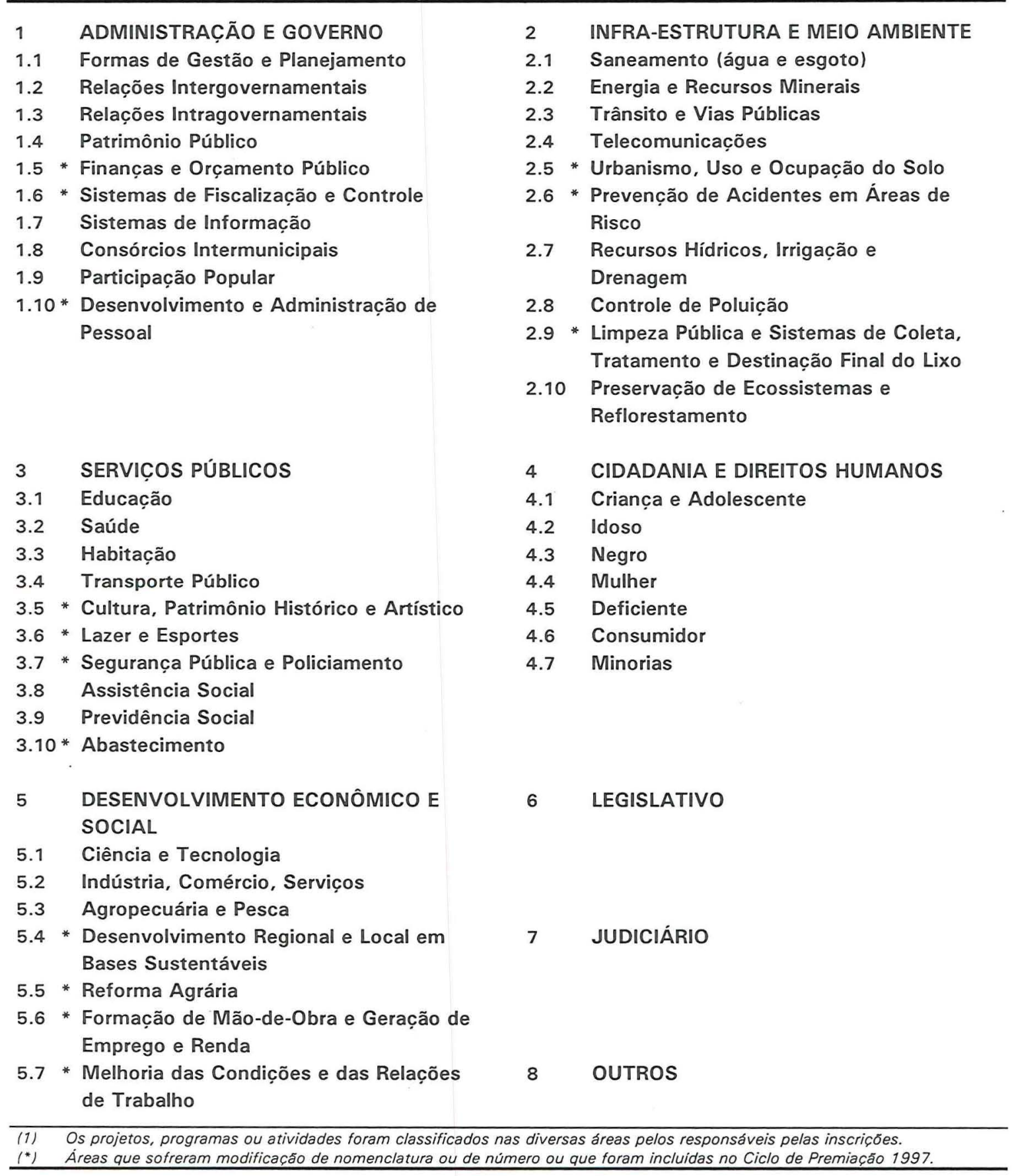


QUADRO III - Questionário-padrão enviado aos 100 semifinalistas do Ciclo de Premiação 1998 do GESTÃo PÚBLICA E CIDADANIA

1. * Liste os objetivos e especifique as metas mais importantes do programa, projeto ou atividade por ordem de prioridade.

2. * Descreva como o programa, projeto ou atividade é concretamente operacionalizado. Qual(is) a(s) sua(s) frente(s) de ação? Caso haja interface com outro(s) projeto(s) ou atividade(s) individualmente ou dentro de um programa maior, indique-o(s), apresentando como se dá essa integração.

3. * Identifique o público-alvo. Quantos são, no momento, os diretamente beneficiados? Que percentual da clientela potencial isto representa? Como é feita a seleção dos beneficiários e como eles participam do programa, projeto ou atividade?

4. Qual é o gasto orçamentário anual do programa, projeto ou atividade? Quais são as fontes de recurso financeiro (locais, estaduais, federais, privadas)? Que percentual dos recursos financeiros anuais é derivado de cada uma dessas fontes? Que percentual de receita orçamentária total do nível de governo (estadual, municipal etc.) a que pertence o órgão responsável pela inscrição é efetivamente utilizado no programa, projeto ou atividade?

5. ** Quantas pessoas estão diretamente envolvidas na operação de seu programa, projeto ou atividade?

6. Indique todas as organizações (públicas e privadas) participantes, descrevendo o papel de cada uma.

7. ** Se seu programa, projeto ou atividade envolve a participação da comunidade e do público-alvo, descreva como esta participação concretiza-se (explique os mecanismos de participação).

8. Quando e como foi originalmente concebido o programa, projeto ou atividade? Houve inspiração em iniciativa(s) anterior(es)? Qual(is)?

9. * Identifique as etapas-chave de implementação e como isto evoluiu e se modificou ao longo do tempo. Que incrementos foram sendo realizados desde o início da operação do programa, projeto ou atividade?

10. Descreva os principais obstáculos enfrentados até o momento. Como se lidou com tais obstáculos? Quais deles ainda persistem?

11. * Que mecanismos de avaliação estão sendo utilizados para medir o sucesso do programa, projeto ou atividade? Forneça os resultados (qualitativos e quantitativos) do último ano de operação do programa, projeto ou atividade.

12. Qual é a mais importante conquista do programa, projeto ou atividade até o momento (cite apenas uma; aquela que, na sua opinião, é a mais importante)?

13. Em que aspectos o programa, projeto ou atividade inovou em relação a práticas anteriores? Procure explicar bem em que consiste a inovação.

14. ** Mesmo que seu programa, projeto ou atividade não focalize especificamente a questão da pobreza, como você avalia seu impacto sobre este problema social?

15. ** Qual o impacto do seu programa, projeto ou atividade sobre a cidadania (por exemplo, em questões de direitos, gênero, raça ou etnia?)

16. * Caso seu programa, projeto ou atividade já tenha participado do Programa GESTÃo PÚBLICA E CIDADANIA em 1996 ou 1997, qual a diferença que ele apresenta neste ano em relação aos anos anteriores?

17. * Qual é a mais significativa deficiência do programa, projeto ou atividade?

$\left.1^{*}\right)$ Questóes que foram incluidas ou que sofreram alteração de texto no Ciclo de Premiação 1997.

$\left.1^{* *}\right)$ Questöes que foram incluidas ou que sofreram alteração de texto no Ciclo de Premiaçáa 1998.

Nosso endereço: Av. Nove de Julho, 2.029, sala 1.059 - São Paulo - SP - 01313-902; telefones (011) 281-7904 e (011) 281-7905; e-mail: inovando@eaesp.fgvsp.br. 